\title{
Announcement: 2011 VNS Young Investigator Award
}

Dr. Tom Baden was awarded the 2011 VNS Young Investigator Award at the biennial European Retina Meeting held in Amsterdam, The Netherlands. Dr. Baden's poster was selected from among 50 eligible poster presentations made during this three day meeting. The work that Dr. Baden presented was conducted in the laboratory of Dr. Thomas Euler at the University of Tübingen, in collaboration with Dr. Robert Smith (University of Pennsylvania), on bipolar cell signaling. Bipolar cells are traditionally thought to signal via graded membrane depolarizations, but recent studies indicate that some bipolar cells in fish retina are capable of firing action potentials. New calcium imaging data were presented by Dr. Baden and colleagues, showing that bipolar cell synaptic terminals in the mouse retina also exhibit spikes. Interestingly, individual terminals on the same bipolar cell were found to operate independently, suggesting that single bipolar cells may transmit multiple channels of visual information to different postsynaptic targets. Numerical simulations suggested that asymmetric inhibition from amacrine cells may give rise to the diversity of responses within a single cell.

The Editors thank the members of the selection committee for serving in this capacity.

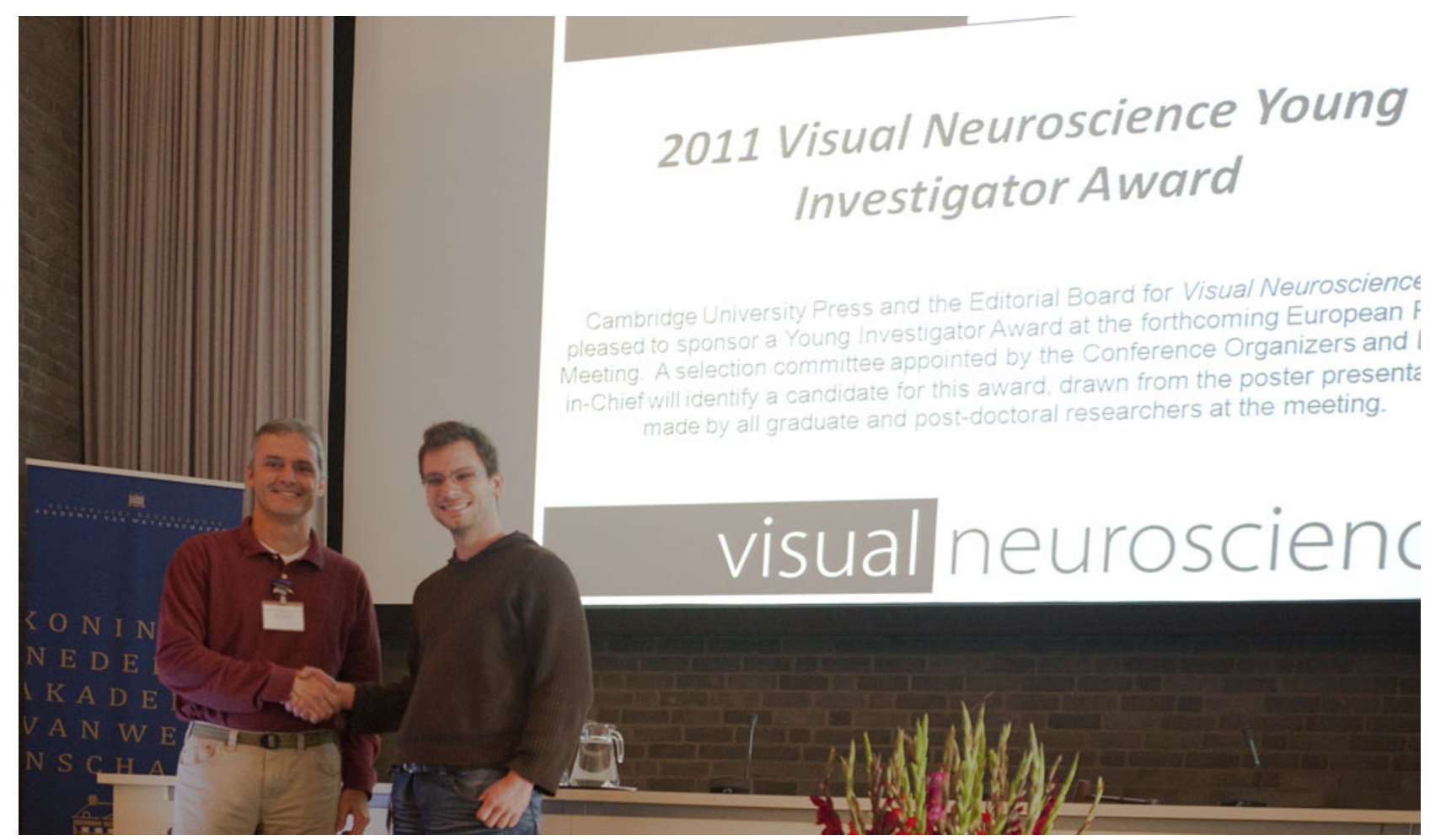

The recipient, Tom Baden (right), being congratulated by chair of the selection committee (and member of the Editorial Board), Dr. Jeff Diamond 